\title{
Hazard-consistent seismic losses and collapse capacities for light-frame wood buildings in California and Cascadia
}

\author{
Robert E. Chase ${ }^{1,2}$ (D) Abbie B. Liel ${ }^{2,4}$ (D) Nicolas Luco ${ }^{1}$ (D) $\cdot$ Zach Bullock $^{3}$ (D) \\ Received: 16 February 2020 / Accepted: 14 October 2021 / Published online: 11 November 2021 \\ (c) The Author(s) 2021
}

\begin{abstract}
We evaluate the seismic performance of modern seismically designed wood light-frame (WLF) buildings, considering regional seismic hazard characteristics that influence ground motion duration and frequency content and, thus, seismic risk. Results show that WLF building response correlates strongly with ground motion spectral shape but weakly with duration. Due to the flatter spectral shape of ground motions from subduction events, WLF buildings at sites affected by these earthquakes may experience double the economic losses for a given intensity of shaking, and collapse capacities may be reduced by up to $50 \%$, compared to those at sites affected by crustal earthquakes. These differences could motivate significant increases in design values at sites affected by subduction earthquakes to achieve the uniform risk targets of the American Society of Civil Engineers (ASCE) 7 standard.
\end{abstract}

Keywords Subduction earthquakes $\cdot$ Collapse $\cdot$ Economic losses $\cdot$ Wood light-frame buildings

\section{Introduction}

Even among regions of high seismic hazard in the United States, significant variation in tectonic environments influences ground motion characteristics and, as a result, seismic risk. For example, the Pacific Northwest "Cascadia" region has both crustal and subduction earthquake sources. The Cascadia subduction zone is capable of producing large

Abbie B. Liel

abbie.liel@colorado.edu

1 U.S. Geological Survey, Geologic Hazards Science Center, Golden, CO, USA

2 Department of Civil, Environmental, and Architectural Engineering, University of Colorado Boulder, Boulder, CO 80401, USA

3 Department of Civil Engineering, The University of British Columbia, Vancouver, BC V6T 1Z4, Canada

41111 Engineering Drive, ECOT 440, UCB 428, Boulder, CO 80309, USA 
magnitude events, generating ground motions with relatively long durations of shaking and elevated frequency content at moderate to long periods compared to crustal ground motions (Furumura et al. 2011). Even considering locations where seismic hazard is only dominated by crustal events, variability in source or hazard characteristics may still alter frequency content or duration patterns in ground motions. For example, although both Los Angeles and San Francisco have only crustal seismic sources, the expected duration and frequency content of ground motions at a given hazard level (return period) differ significantly between the two cities, due to larger contributions from greater magnitude earthquakes in San Francisco (Petersen et al. 2014).

Yet, building standards and codes in the United States (ICC 2018; ASCE 2016) and elsewhere do not generally consider ground motion duration or spectral shape (i.e., frequency content at periods other than the fundamental period) in the design of new buildings except in rare cases where nonlinear response history analysis is used. Thus, although the ASCE 7 standard (ASCE 2016) now explicitly targets specific risk goals (i.e., 1\% probability of collapse in 50 years for ordinary, Risk Category II structures), these goals may not be uniformly achieved due to differences in seismic hazard at different sites and the resulting ground motion characteristics that affect response and risk.

Here, we are concerned with ground motion characteristics beyond spectral acceleration at a single period $(\mathrm{Sa})$, which is already mapped and incorporated into seismic design procedures. Several studies (e.g., Raghunandan and Liel 2013; Chandramohan et al. 2016; Pan et al. 2018) have shown that longer duration shaking causes buildings to collapse at lower values of $S a$. Duration has a smaller influence on peak response parameters, such as story drifts, than collapse, but this influence is more significant when shaking is more intense and behavior is nonlinear (Iervolino et al. 2006; Hancock and Bommer 2007; Mohammed et al. 2015; Chandramohan 2016). Spectral shape can significantly influence structural response because, as a structure responds nonlinearly and its period elongates, spectral energies at periods other than the fundamental period of the structure become important (e.g., Baker and Cornell 2006; NIST 2011; and many others). As a result, many authors (e.g., Eads et al. 2016; Marafi et al. 2017) have shown that, for ground motions with the same spectral acceleration at the fundamental period of a structure, $S a\left(T_{1}\right)$, motions with spectra indicating higher energy at periods away from fundamental period are more damaging than motions with low spectral energy at the surrounding periods.

These trends can significantly affect seismic risk. Raghunandan et al. (2015) found that the median collapse capacity of modern concrete buildings decreased by $36 \%$ when subjected to ground motions from subduction rather than crustal earthquakes. They attributed this elevated collapse risk to the longer durations and greater spectral energies at longer periods characteristic of ground motions from subduction earthquakes. Chandramohan et al. (2016) concluded that the mean annual frequencies of collapse were underestimated in Seattle, WA, and Eugene, OR, by $29 \%$ and $59 \%$, respectively, if the impacts of duration and spectral shape from subduction earthquakes were not considered. Likewise, Marafi et al. (2017) examined the collapse risk of structures in Seattle, showing that both the characteristics of subduction earthquakes and the Seattle Basin alter ground motion properties with the effect of increasing collapse risk.

We quantified seismic performance, in terms of economic losses and collapse risk, in wood light-frame (WLF) buildings, considering tectonic-environment seismic hazard characteristics that influence ground motion duration and frequency content of shaking. To do so, we simulate the seismic response of six archetypes of residential and commercial WLF buildings of various heights at six locations in the western United States. We employ and advance the implementation of the hazard-consistent incremental dynamic analysis 
Table 1 Properties of the six sites considered in this study

\begin{tabular}{lllll}
\hline Site & Latitude [degrees] & Longitude [degrees] & SDC & $\mathrm{S}_{\mathrm{DS}}[\mathrm{g}]^{*}$ \\
\hline Los Angeles, CA & 33.9960 & -118.1620 & $\mathrm{D}$ & 1.47 \\
San Francisco, CA & 37.7800 & -122.4030 & $\mathrm{D}$ & $1.20^{* *}$ \\
Seattle, WA & 47.6071 & -122.3358 & $\mathrm{D}$ & 1.12 \\
Portland, OR & 45.5207 & -122.6789 & $\mathrm{D}$ & 0.71 \\
Anchorage, AK & 61.2156 & -149.8956 & $\mathrm{D}$ & $1.20^{* *}$ \\
Eugene, OR & 44.0500 & -123.0900 & $\mathrm{D}$ & 0.58 \\
\hline
\end{tabular}

The sites are listed in order from lowest subduction contribution to largest, based on percent of hazard shown in Fig. 1

*Design spectral acceleration response parameter, based on ASCE 7-16, assuming site class B/C boundary

**Site design value is controlled by the deterministic cap (Luco et al. 2017)

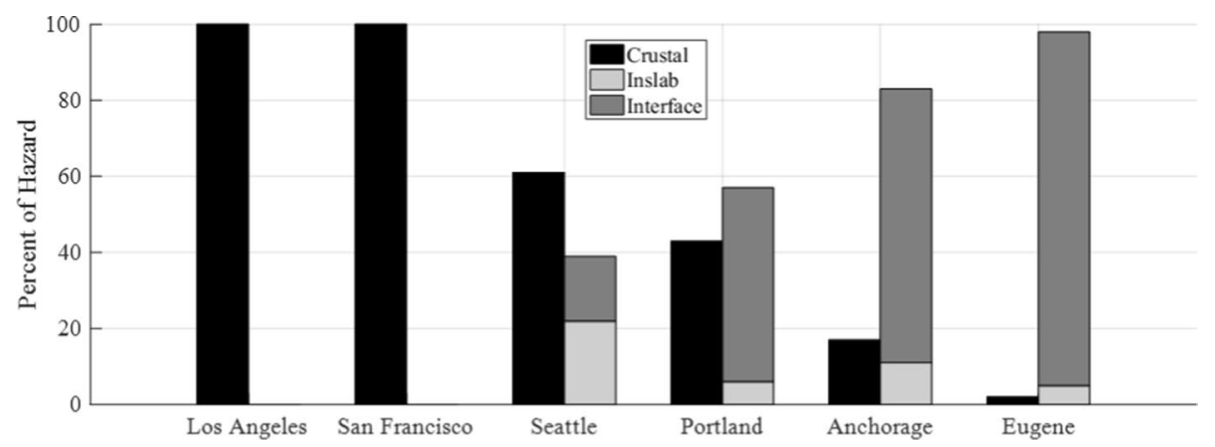

Fig. 1 Contribution of crustal and subduction (inslab and interface) source types to seismic hazard at selected sites at the 2475-year hazard level for $S a(T=0.3 \mathrm{~s})$. Disaggregation at $S a(T=0.3 \mathrm{~s})$ was selected as a reasonable summary representation of the hazard because building periods range from 0.19 to $0.62 \mathrm{~s}$, as described in Table 2

methodology, developed by Chandramohan (2016), to develop hazard-consistent structural response predictions that feed into estimations of economic losses and collapse risk at each site, and evaluate the influence of tectonic environment. We also propose modifications to design base shear that achieve more uniform risk among the sites. We focus on WLF buildings because they compose the majority of the U.S. building stock and will contribute significantly to impacts from a large earthquake.

\section{Methods}

\subsection{Sites}

We considered six sites in the western United States (Table 1), all of which fall in seismic design category (SDC) D for the site class B/C boundary, as determined by ASCE 7 (2016). These sites were selected to investigate a range of tectonic environments, as illustrated in Fig. 1, which show very different influence of subduction and crustal sources at the various sites. Here, crustal sources are those that do not occur within a subduction 
zone and originate along fault lines at plate boundaries or within the plate itself. Inslab and interface earthquakes both originate from a subduction zone, with interface earthquakes occurring at the contact zone between the two plates and inslab earthquakes occurring deeper, within the subducting plate.

\subsection{Building archetypes and modeling}

We consider six archetype buildings that are representative of modern buildings in the western United States, as detailed in Table 2. These buildings were designed by the Applied Technology Council (ATC) 116 project team (Ghehnavieh 2017; FEMA 2020a, b), according to ASCE 7 (ASCE 2010). All building designs are intended for locations at the upper end of SDC D, with an $\mathrm{S}_{\mathrm{DS}}$ of $1.0 \mathrm{~g}$. We investigate the response of the six buildings in the six cities without redesigning each building at each site. As a result, the buildings are overdesigned for Eugene and Portland, and underdesigned at the other sites; the implications of inconsistency in the design values are described in the results.

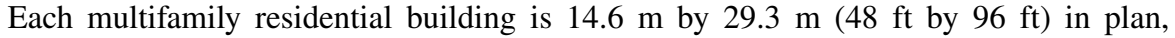
accommodating six $7.3 \mathrm{~m}$ by $9.8 \mathrm{~m}(24 \mathrm{ft}$ by $32 \mathrm{ft})$ adjacent units per floor in the one- and four-story buildings, as shown in Fig. 2. The exterior walls are framed with $3.8 \mathrm{~cm}$ by $14 \mathrm{~cm}(2 \times 6$ nominal) lumber, with exterior faces clad in stucco over $1.1 \mathrm{~cm}(7 / 16 \mathrm{in})$ oriented-strand-board (OSB). The interior face of the exterior walls is clad with $1.3 \mathrm{~cm}$ (1/2 in) gypsum wall board. The interior shear walls (party walls) are actually two lines of $3.9 \mathrm{~cm}$ by $8.9 \mathrm{~cm}(2 \times 4$ nominal $)$ framing separated by a $2.5 \mathrm{~cm}$ (1 in) gap, which would in reality be a larger corridor, to resemble typical construction practices. The two-story building has four two-story townhouses, with each townhouse unit sitting on a $7.3 \mathrm{~m}$ by $14.6 \mathrm{~m}$ ( $24 \mathrm{ft}$ by $48 \mathrm{ft}$ ) footprint. More detailed descriptions of the building designs are provided elsewhere (Ghehnavieh 2017; Chase 2018; FEMA 2020a, b).

The three commercial buildings have the same footprint as the residential buildings, but the former have shear walls located only around the perimeter, as indicated by Fig. 3. The one-story building has no (interior) nonstructural partition walls, representing typical commercial occupancies. Instead, gravity loads and the floor and roof trusses are supported by interior steel girders at $7.3 \mathrm{~m}(24 \mathrm{ft})$ on center, which span to steel posts and perimeter wood bearing walls. These steel posts do not contribute to the lateral force resisting system.

Table 2 Archetype building characteristics. V is the design base shear and $\mathrm{W}$ is the effective seismic weight as defined in ASCE 7-16

\begin{tabular}{llllllll}
\hline Building ID & Occupancy & Stories & $\begin{array}{l}\text { Period } \\
\mathrm{T}_{1}[\mathrm{~s}]^{*}\end{array}$ & $\begin{array}{l}\text { Seismic } \\
\text { Weight } \\
{[\mathrm{kN}]}\end{array}$ & $\begin{array}{l}\text { Design } \\
\mathrm{C}_{\mathrm{s}}=\mathrm{V} / \mathrm{W}\end{array}$ & $\begin{array}{l}\text { Ductility } \\
\mu_{\mathrm{T}}{ }^{* * *}\end{array}$ & $\begin{array}{l}\text { Overstrength } \\
\Omega_{0}{ }^{* * *}\end{array}$ \\
\hline MFD1 & Residential & 1 & 0.19 & 630 & 0.154 & 4.8 & 7.9 \\
MFD2 & Residential & 2 & 0.29 & 1450 & 0.154 & 4.5 & 4.7 \\
MFD4 & Residential & 4 & 0.51 & 3830 & 0.154 & 6.1 & 2.6 \\
COM1 & Commercial & 1 & 0.33 & 800 & 0.154 & 4.6 & 3.2 \\
COM2 & Commercial & 2 & 0.39 & 1970 & 0.154 & 4.7 & 3.1 \\
COM4 & Commercial & 4 & 0.62 & 4310 & 0.154 & 2.8 & 2.2 \\
\hline
\end{tabular}

*Fundamental period of building, as determined from the simulation model. Periods are similar in the building's two orthogonal directions

**Calculated per FEMA P-695 (2009) Eqs. 6-5 and 6-6 


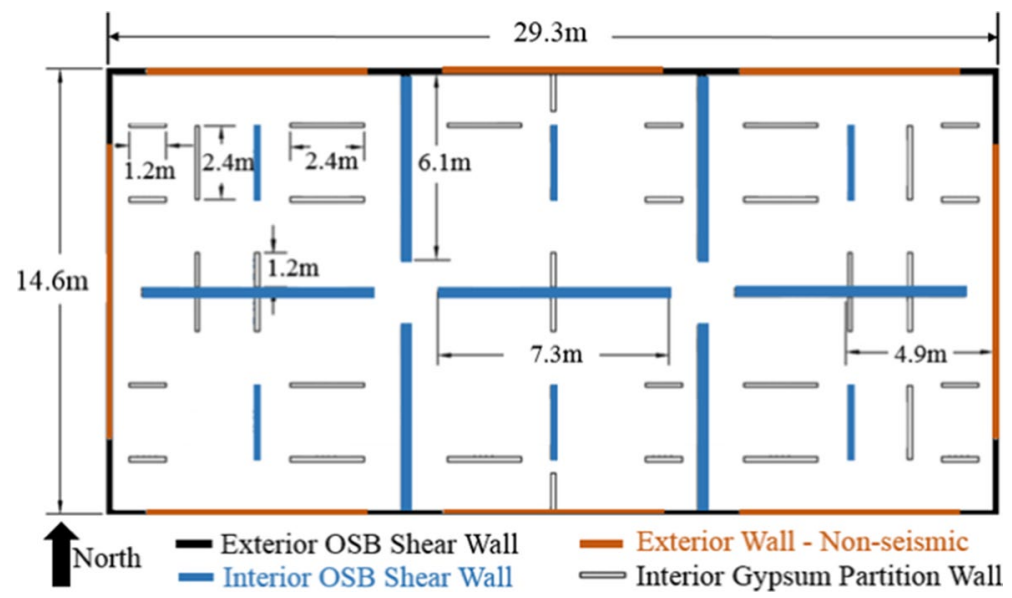

Fig. 2 Plan view of the one-story multifamily building. (Modified from image provided by D. Jared DeBock.)

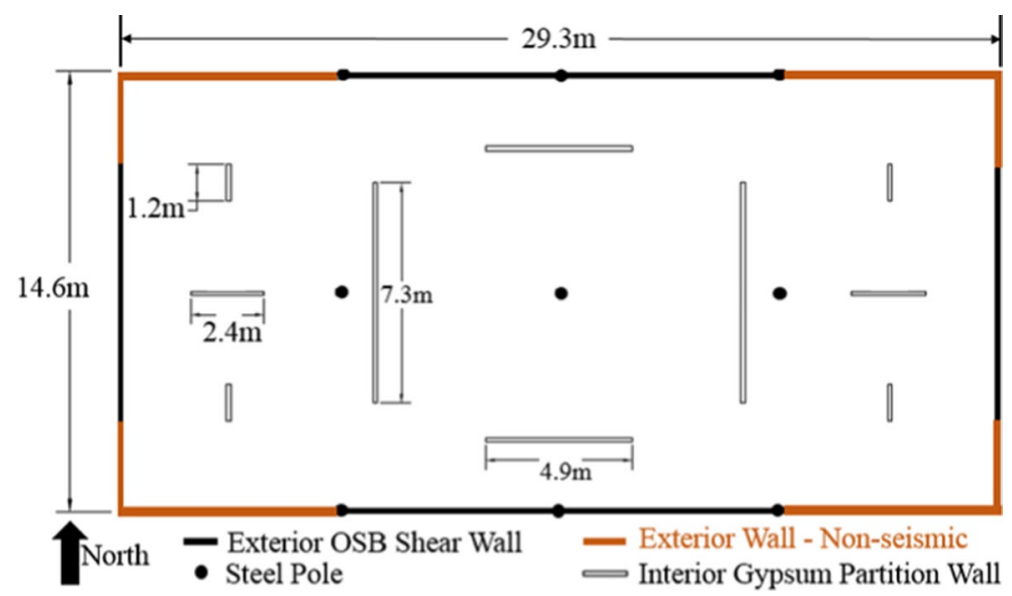

Fig. 3 Plan view of the two- and four-story commercial buildings. (Modified from image provided by D. Jared DeBock.)

Other details of the designs are provided elsewhere (Ghehnavieh 2017; Chase 2018; FEMA 2020a, b).

\subsection{Modeling}

The buildings are modeled in three dimensions using Timber $3 D$, a nonlinear structural analysis software for wood frame construction that was developed by Pang et al. (2012) and Pang and Shirazi (2013). The software is intended for simulating the seismic response of three-dimensional (3D) WLF building systems. It captures individual wood frame elements and the interaction of their responses up to large horizontal and vertical displacements. Timber3D improves upon the so-called lumped parameter approach of SAWS (Folz 
and Filiatrault 2004a,b) and SAPWood (Pei and van de Lindt 2011), by employing a finite element methodology with nodal condensation to decrease computational expense. In this study, in which we aim to simulate response up to collapse, it is particularly important to capture and distinguish between cyclic and in-cycle degradation as well as large deformations and geometric (P-delta) effects (Pang et al. 2012; Ghehnavieh 2017), all of which are incorporated in these models. These models were originally developed by the ATC 116 project and were provided by Ghehnavieh (2017).

Nonlinear material behavior is modeled only in the wall elements. Wall elements include both the shear walls, which in the designs are taken to be the sole lateral force resisting system in the structure, and the interior partition walls. The hysteretic model that defines the nonlinear wall elements and finishes is a modification to the Modified Stewart Hysteretic Model, which was developed based on experimental testing of wood shear walls under quasi-static loading (Folz and Filiatrault 2001). The modification developed by Ghehnavieh (2017) follows the same hysteretic response but replaces linear degradation of the post-peak strength with an " $\mathrm{S}$ " curve to represent residual strength observed at large displacements in wood shear walls. Model parameters for each wall element were calibrated by Ghehnavieh (2017) to experiments, as a function of wall length, nail spacing, and stud spacing. Figure 4 shows the hysteretic characteristics for sections of an exterior shear wall and interior partition wall. These plots show the nonlinear response for the walls excluding nonstructural finishes and the effect of the exterior stucco finish separately. These elements are assigned to the same location such that the composite wall response combines structural and nonstructural contributions.

The base of each structure is modeled with multiple elements to simulate the effects of hold downs, anchor bolts, sill plates, and the concrete foundation. In the models here, the concrete foundation, sill plates, stud elements, and floor diaphragms are modeled as elastic elements, and the hold downs and anchor bolts are rigid. The result is an effectively fixed base.

We define collapse as $10 \%$ drift in any story, in either of the two horizontal directions independently, following Pei et al. (2012). As determined in our analysis, this drift is typically associated with large downward (vertical) displacement (e.g., greater than 10 in) due to large geometric deformations and corotational effects.

Damping in WLF buildings is largely controlled by the nonlinear hysteresis of components such as shear walls (Filiatrault et al. 2003), which is considered in the hysteretic calibration of the wall elements. In accordance with other studies (Pang and Shirazi 2013; van de Lindt et al. 2009), we add a small amount (1\%) of Rayleigh damping to capture damping when the model is responding elastically. At collapse levels, this damping does not significantly impact the results, indicating we have avoided overdamping the nonlinear response.

Fig. 4 Force vs. displacement hysteresis of $1.2 \mathrm{~m}$ wide by $3 \mathrm{~m}$ tall ( $4 \mathrm{ft}$ by $10 \mathrm{ft}$ ) sections of an OSB shear wall, an interior gypsum partition wall, and exterior stucco finish found in all archetypes

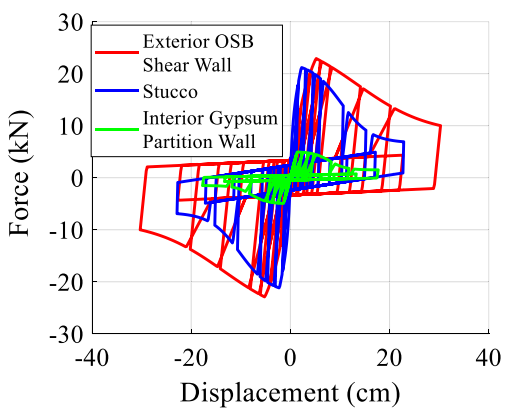


The monotonic pushover (lateral force vs. displacement) curves for all archetype buildings in both the horizontal directions are compared in Fig. 5, with other key details provided in Table 2. The buildings' overstrengths, or ratio of ultimate strength to design base shear, are significant, because we model the effects of nonstructural partition walls and nonstructural finishes on all walls. The residential archetypes have higher overstrengths than the commercial archetypes of the same height, due to the larger number of internal walls. We note also that our study buildings have higher overstrengths and are less ductile than similar archetype buildings examined in FEMA P-695 Section 9.4 (FEMA 2009; FEMA 2020a, b). These differences are due to the inclusion of nonstructural finishes such as stucco and gypsum wallboard in the models, which add strength and stiffness, but reduces deformation capacity of the system (when deformation capacity is measured relative to a loss of strength of the component wall system).

\subsection{Hazard-consistent IDA method}

Incremental dynamic analysis (IDA) is a method advanced by Vamvatsikos and Cornell (2002) for dynamic simulation of the seismic response of a structure. IDA involves scaling an input ground motion of interest up incrementally, recording structural response at each scale level, until collapse is reached. IDA is convenient because a single set of ground motions can be used to obtain estimates of structural response across a range of intensity levels, including at high, rarely recorded intensities. However, the scaled ground motions may not have the appropriate characteristics (e.g., frequency content, duration), biasing structural response predictions (e.g., Vamvatiskos and Cornell 2002; Baker and Cornell 2006; many others). Multiple stripe analysis (MSA) addresses these limitations by providing a procedure for selecting different ground motion sets for each intensity level of interest (Jalayer 2003); characteristics of the ground motions are selected to be consistent with the site hazard at that intensity level. However, MSA is intractable here because it would require selecting and applying distinct ground motion sets for each building at each site for each intensity level of interest. Instead, we adopt the hazard-consistent (HC) IDA procedure proposed by Chandramohan (2016). HC-IDA uses a generic set of ground motions in IDA but develops a postprocessing adjustment of the structural response results such that they are consistent with hazard characteristics at the site and intensity levels of interest. Chandramohan (2016) showed that this approach provides structural response and risk outcomes similar to MSA.
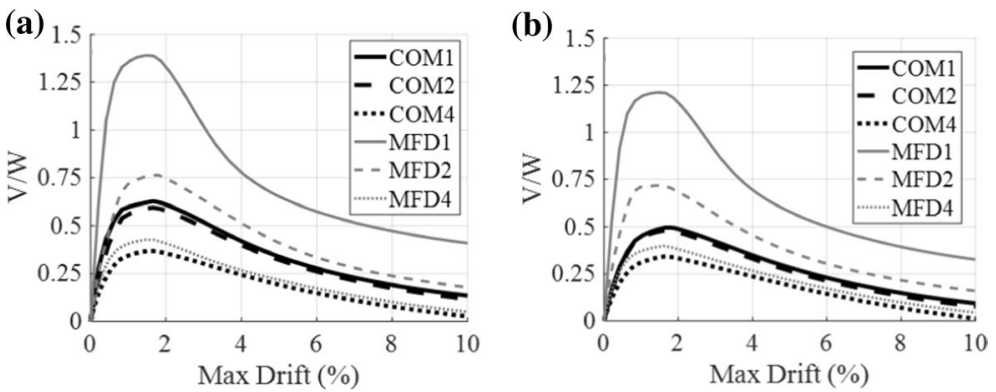

Fig. 5 Pushover curves for the archetype buildings in the a longer (E-W) and b shorter (N-S) plan directions, considering distributed loading according to the first mode shape 
In the HC-IDA methodology (Chandramohan 2016; Zhong et al. 2021), first, seismic hazard disaggregation information is used to acquire earthquake characteristics (e.g., magnitude) and their contribution to the hazard at the site and each hazard level of interest. These earthquake characteristics are then fed into ground motion prediction equations (GMPEs) to produce expected ground motion characteristics at each site for each intensity level; these values are called "target" intensity measures (IMs). Here, we focus on IMs for spectral shape and duration, though HC-IDA is extendable to other characteristics (Bradley 2010).

Not yet considering the target IMs, we subject all building models to the same generic ground motions through IDA. These IDA results are fed into a multivariate regression analysis to relate the IMs of interest, i.e., spectral shape and duration, to structural response parameters of interest. From this regression, the results of the IDA are adjusted to be consistent with the target IMs, producing median, hazard-consistent structural response results. These calculations are based on Chandramohan (2016) and Zhong et al. (2021) but update underlying models for ground motions and correlations. Each step is described in detail below.

The outcome of HC-IDA is hazard-consistent collapse capacities and additional hazard-consistent engineering demand parameters (EDPs). The hazard-consistent collapse capacities are examined to provide insight into potential modifications to design base shears at each site. The hazard-consistent EDPs are used as input into the FEMA P-58 methodology (FEMA 2012) to produce hazard-consistent economic loss estimates at each site.

\subsection{Duration and spectral shape intensity measures}

We quantify spectral shape by the dimensionless parameter, SaRatio (Eads et al. 2016), and duration by "significant duration," or the time between the accumulation of 5 and $75 \%$ of the Arias intensity, $D s_{5-75}$ (Trifunac and Brady 1975). These choices are supported by Chandramohan (2016)'s evaluation of the efficiency of these IMs, showing these to be strong predictors of structural response. Equally important, hazard information and GMPEs are available for these IMs.

$\operatorname{SaRatio}\left(T_{l}, T_{u}\right)$ is $S a\left(T_{1}\right)$ normalized by $S a_{a v g .} S a_{a v g}$ is the average $S a$ across a range of periods defined by $T_{l}$ and $T_{u}$. A higher SaRatio indicates a ground motion with a more peaked (less damaging) spectrum. For $S a_{\text {avg }}$, Eads et al. (2015) investigated a set of moment frame structures and recommended a period range of $0.2 T_{1}$ to $3 T_{1}$. We adopt instead a period range of $T_{1}$ to $3 T_{1}$. For these low-rise, short-period structures, higher modes, i.e., $T<T_{1}$, are not critical; we found that the responses of the buildings studied here correlate better with SaRatio defined with this period range (Chase 2018).

We modify the traditional definition of $D s_{5-75}$ based on Walling et al. (2018) and refer to the modified metric as $D s_{5-75, N G A} . D s_{5-75, N G A}$ quantifies only the most intense duration of shaking (based on the derivative of the Arias intensity Husid plot). The result is that ground motions that have multiple, separated durations of strong energy have shorter calculated durations in the modified definition relative to the conventional definition, because the low energy portion of the motion that separates periods of strong shaking is excluded from the duration calculation. This modification can be significant for subduction motions or in events that rupture multiple faults but has a small impact for most of the available crustal records. 


\subsection{Seismic hazard disaggregation}

For each site, seismic hazard disaggregation information is acquired from the 2014 National Hazard Model (Petersen et al. 2014; USGS 2018). Disaggregations are conducted at each site for the $\mathrm{B} / \mathrm{C}$ site class boundary $\left(V_{s 30}=760 \mathrm{~m} / \mathrm{s}\right)$ for nine different hazard levels (defined by their return period in years) at three periods near the fundamental periods (Table 2) of the buildings: $0.2 \mathrm{~s}, 0.3 \mathrm{~s}$ and $0.5 \mathrm{~s}$. Disaggregation information includes moment magnitude $\left(\mathrm{M}_{\mathrm{W}}\right)$, distance between the rupture surface and site $(R)$, source type (crustal, inslab, interface), and percent contribution to the total hazard. It also quantifies epsilon $(\varepsilon)$, defined as the number of standard deviations by which a $S a$ of interest differs from the mean predicted $S a$ from a GMPE (in log space).

Table 3 provides one such disaggregation, at a period of $0.3 \mathrm{~s}$ in Eugene. For this case, the contribution of crustal hazards falls significantly for the longer return period hazard levels, and the contribution from subduction interface events increases. Magnitude increases and site-to-source distance decreases for each source type with increasing hazard level. $\varepsilon$ also increases as the hazard level increases, indicating a more peaked spectrum at longer return periods. Seismic hazard disaggregations for Los Angeles and San Francisco reveal $100 \%$ crustal sources but follow the same trends with magnitude, distance, and $\varepsilon$ as Eugene (Chase 2018). Like Eugene, Portland and Anchorage exhibit an increasing subduction contribution with longer return period hazard level. Conversely, in Seattle, crustal contribution increases at longer return periods due to a $\mathrm{M}_{\mathrm{W}} \approx 6.5$ crustal earthquake scenario that contributes significantly to the hazard. At all sites, although several short periods of interest are considered, the disaggregations are similar.

\subsection{Ground motion prediction equations and correlations}

The GMPEs used for $S a$ and significant duration for different source types (Table 4) are used to determine expected $S a$ and duration from the magnitudes and site-to-source distances obtained from the disaggregations (e.g., Table 3). Details about other GMPE inputs, including other rupture distance parameters, are provided in Chase (2018).

The Walling et al. (2018) duration GMPE is preliminary and does not have a site term. Previous authors have shown that a site term avoids bias with site conditions in duration

Table 3 Seismic hazard disaggregation from the 2014 USGS Hazard Model for $T=0.3 \mathrm{~s}$ in Eugene, reporting mean $\mathrm{M}_{\mathrm{W}}, R$, and $\varepsilon$, and percent contribution for each source type at each hazard level

\begin{tabular}{|c|c|c|c|c|c|c|c|c|c|c|c|c|c|}
\hline \multirow{2}{*}{$\begin{array}{l}\text { Hazard } \\
\text { Level [yr] }\end{array}$} & \multirow[t]{2}{*}{$\mathrm{Sa}(\mathrm{T}=0.3 \mathrm{~s})[\mathrm{g}]$} & \multicolumn{4}{|c|}{ Crustal } & \multicolumn{4}{|c|}{ Inslab } & \multicolumn{4}{|c|}{ Interface } \\
\hline & & $\mathrm{M}_{\mathrm{W}}$ & $\mathrm{R}[\mathrm{km}]$ & $\varepsilon$ & $\%$ & $\mathrm{M}_{\mathrm{W}}$ & $\mathrm{R}[\mathrm{km}]$ & $\varepsilon$ & $\%$ & $\mathrm{M}_{\mathrm{W}}$ & $\mathrm{R}[\mathrm{km}]$ & $\varepsilon$ & $\%$ \\
\hline 75 & 0.03 & 6.4 & 121 & 0.3 & 65 & 6.9 & 128 & -1.2 & 11 & 8.7 & 108 & -2.8 & 24 \\
\hline 275 & 0.13 & 6.5 & 63 & 0.7 & 17 & 6.9 & 92 & -0.3 & 15 & 8.8 & 98 & -1.1 & 68 \\
\hline 475 & 0.23 & 6.5 & 40 & 0.8 & 8 & 6.9 & 80 & 0.2 & 13 & 8.8 & 93 & -0.4 & 80 \\
\hline 975 & 0.40 & 6.5 & 25 & 0.9 & 4 & 7.0 & 71 & 0.7 & 10 & 8.9 & 85 & 0.2 & 86 \\
\hline 2475 & 0.69 & 6.5 & 17 & 1.2 & 3 & 7.0 & 64 & 1.1 & 9 & 8.9 & 79 & 0.8 & 89 \\
\hline 4000 & 0.87 & 6.5 & 15 & 1.3 & 2 & 7.0 & 62 & 1.3 & 8 & 8.9 & 76 & 1.0 & 90 \\
\hline 6000 & 1.03 & 6.5 & 13 & 1.4 & 2 & 7.1 & 61 & 1.5 & 7 & 9.0 & 75 & 1.2 & 91 \\
\hline 8000 & 1.16 & 6.6 & 12 & 1.5 & 2 & 7.1 & 60 & 1.6 & 7 & 9.0 & 73 & 1.3 & 91 \\
\hline 10,000 & 1.26 & 6.6 & 11 & 1.5 & 2 & 7.1 & 59 & 1.7 & 7 & 9.0 & 73 & 1.4 & 92 \\
\hline
\end{tabular}




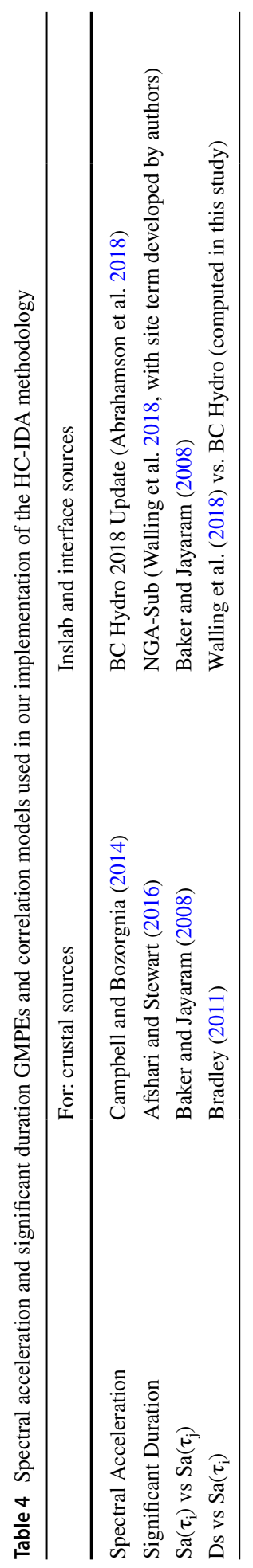


GMPEs (e.g., Bommer et al. 2009; Afshari and Stewart 2016). Accordingly, we apply nonlinear regression using about 1600 strong motion records taken from interface and inslab earthquakes in the New Zealand Strong Motion Database (Van Houtte et al. 2017) to formulate a site term for use with the Walling et al. (2018) GMPE based on $V_{s 30}$. The details of this regression and the proposed additional term are provided in Chase (2018).

The crustal duration GMPE from Afshari and Stewart (2016) produces the traditional definition of $D s_{5-75}$, whereas the subduction duration GMPE from Walling et al. (2018) produces $D s_{5-75, N G A}$. To make calculations at sites with both crustal and subduction hazards, we convert $D s_{5-75}$ to $D s_{5-75, N G A}$. For this purpose, $D s_{5-75}$ and $D s_{5-75, N G A}$ are calculated for the far field set of crustal records from FEMA P-695 (2009), and a linear regression was performed between $D s_{5-75}$ and $D s_{5-75, N G A}$, showing that $D s_{5-75, N G A}=0.896 D s_{5-75}$ with an $\mathrm{R}^{2}=0.93$ for typical far field crustal records. We note the duration definition proposed by Walling et al. (2018) has not yet been shown to correlate well with structural response. However, as this regression indicates, $D s_{5-75, N G A}$ is correlated strongly with $D s_{5-75}$, which previous authors have shown to be well correlated with response (e.g., Bommer et al. 2009; Chandramohan 2016).

The duration GMPEs (Fig. 6) for larger magnitude earthquakes estimate longer durations for crustal earthquakes than for subduction earthquakes at the same distance. Thus, subduction events tend to produce long-duration ground shaking primarily because of the large distances and magnitudes associated with these earthquakes, as well differences from path effects. Walling et al. (2018) predict a longer duration for interface earthquakes compared to inslab earthquakes of the same magnitude for large distances because of the multiple slips experienced in large interface earthquakes that increase ground motion duration, even considering that Walling et al. (2018) remove the pauses between these slips. For sites with exclusively seismic hazard from crustal sources, like San Francisco and Los Angeles, Afshari and Stewart (2016) predict steeply increasing duration for magnitudes exceeding roughly $M_{w}$ 7.2. Although this relationship was developed for magnitudes up to $M_{w} 8.0$, its use may result in relatively long target durations for San Francisco's hazard (which is dominated by $6.9<\mathrm{M}_{\mathrm{w}}<7.5$ ). Recently, Bahrampouri et al. (2020) also produced models for significant duration in shallow crustal and subduction earthquakes based on data from $\mathrm{KiK} / \mathrm{K}-\mathrm{Net}$. We use Afshari and Stewart (2016) and Walling et al. (2018) because their global databases are more consistent with the selected models for $S a$ (Campbell and Bozorgnia 2014; Abrahamson et al. 2018, respectively).

SaRatio is obtained from the $\mathrm{Sa}$ GMPEs, considering epsilon from disaggregation and correlations between spectral values at different periods following the Conditional Mean Spectrum approach (Baker 2011; Chandramohan 2016; Eads et al. 2016). Table 4 lists the correlation models used here. We select Baker and Jayaram (2008) for period-to-period

Fig. 6 Significant duration,

$D s_{5-75, N G A}$, plotted for a range of magnitudes and site-to- source distances for the selected duration GMPEs

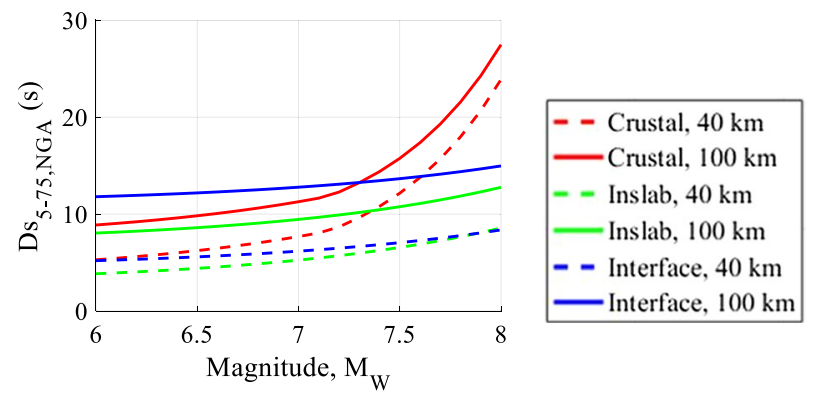


$S a$ correlations for all source types because these correlations have been shown to be relatively insensitive to the tectonic environment.

We also need correlations between $S a$ and $D s_{5-75}$ in each of the tectonic environments. We adopt Bradley (2011) for this purpose in crustal environments, consistent with Chandramohan (2016). Although Bradley (2011) was originally developed for the typical definition of $D s_{5-75}$, its correlation coefficients do not change for $D s_{5-75, N G A}=0.896 D s_{5-75}$ (i.e., multiplication of a variable in linear space or addition in log space does not affect its correlation coefficient with another variable). For subduction environments, we computed correlation coefficients between residuals from the modified Walling et al. (2018) and Abrahamson et al. (2018) using the previously mentioned New Zealand dataset. The values of these correlation coefficients are reported in Chase (2018) Appendix A.4.

\subsection{Target SaRatios and significant durations}

The disaggregation results and GMPE and correlation models are used to calculate target duration and SaRatio IMs, conditioned on each hazard level and source type (Chandramohan 2016). We weight the contributions of multiple source types using a weighted average. As an example, the calculated target $I M s$ at $T=0.3 \mathrm{~s}$ at two sites are reported in Table 5. Due to its subduction sources, Eugene's target $I M S$ indicate higher long-period energy (lower SaRatio) and longer duration shaking than the crustal earthquake scenarios that dominate the hazard in Los Angeles. In Eugene, perhaps counterintuitively, the expected duration generally decreases for the longer return period hazard levels due to two competing factors. As shown in Table 3, for the longer return periods, the mean magnitude from disaggregation increases and distance decreases. These trends have opposite effects on duration of shaking, but decreasing distance influences duration more. In particular, in Eugene, the increase in magnitude is much smaller when compared to the decrease in siteto-source distance across hazard levels, contributing to the trend observed. This trend is much more prominent in Eugene relative to Los Angeles because of the much greater siteto-source distances associated with subduction earthquakes relative to crustal earthquakes.

The target IMs for other sites are shown for selected hazard levels in Fig. 7; IMs for all periods, sites, and hazard levels are reported in Chase (2018). Although, Eugene has the highest target durations overall, San Francisco has higher expected durations

Table 5 Target $I M s$ for Eugene and Los Angeles at $T=0.3 \mathrm{~s}$

\begin{tabular}{|c|c|c|c|c|c|c|}
\hline \multirow{2}{*}{$\begin{array}{l}\text { Hazard } \\
\text { Level [yr] }\end{array}$} & \multicolumn{3}{|l|}{ Los Angeles } & \multicolumn{3}{|l|}{ Eugene } \\
\hline & $\mathrm{Sa}(\mathrm{T}=0.3 \mathrm{~s})[\mathrm{g}]$ & $\begin{array}{l}\text { SaRatio } \\
(0.3,0.9)\end{array}$ & $D s_{5-75, N G A}[\mathrm{~s}]$ & $\mathrm{Sa}(\mathrm{T}=0.3 \mathrm{~s})[\mathrm{g}]$ & $\begin{array}{l}\text { SaRatio } \\
(0.3,0.9)\end{array}$ & $D s_{5-75, N G A}[\mathrm{~s}]$ \\
\hline 75 & 0.26 & 2.1 & 4.8 & 0.03 & 1.4 & 12.2 \\
\hline 275 & 0.57 & 2.3 & 4.3 & 0.13 & 1.3 & 13.4 \\
\hline 475 & 0.76 & 2.4 & 4.2 & 0.23 & 1.3 & 12.5 \\
\hline 975 & 1.08 & 2.5 & 4.2 & 0.40 & 1.4 & 11.1 \\
\hline 2475 & 1.59 & 2.7 & 4.1 & 0.69 & 1.5 & 9.8 \\
\hline 4000 & 1.90 & 2.8 & 4.1 & 0.87 & 1.5 & 9.3 \\
\hline 6000 & 2.20 & 2.9 & 4.0 & 1.04 & 1.7 & 8.9 \\
\hline 8000 & 2.40 & 3.0 & 4.1 & 1.16 & 1.6 & 8.8 \\
\hline 10,000 & 2.57 & 3.0 & 4.0 & 1.26 & 1.6 & 8.5 \\
\hline
\end{tabular}



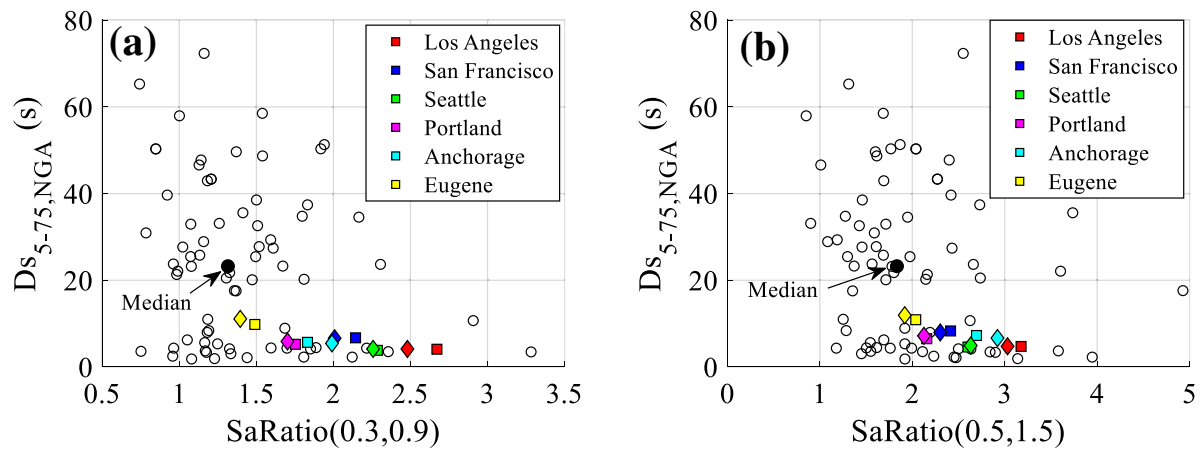

Fig. 7 Scatterplot of $D s_{5-75, N G A}$ versus SaRatio from generic ground motion set, compared with target IMs at each site at the 975-year (diamond) and 2475-year (square) hazard levels. SaRatios are defined with period ranges consistent with a MFD2 and b MFD4

than some of the subduction sites. These longer durations are due to high-magnitude $\left(\mathrm{M}_{\mathrm{W}}>7.2\right)$ scenarios that contribute to the San Francisco hazard disaggregation. When coupling these expected hazards with the predictions from the Afshari and Stewart (2016) crustal duration GMPE (Fig. 6), the result is longer expected durations than predicted from the employed subduction duration GMPE. Seattle has lower expected durations, and more peaked spectra (higher SaRatio), when compared to the other sites with subduction hazards, due to the relatively low-magnitude crustal Seattle fault. However, Seattle sits atop a deep sedimentary basin, which amplifies long-period frequency content (Marafi et al. 2017). The 2014 National Hazard Model (Petersen et al. 2014) and, as a result, these disaggregations, do not consider these basin effects.

\subsection{Ground motion suite}

We use 72 pairs of ground motions that have a range of spectral shapes and durations for the generic ground motion set used in the IDA analysis. This set includes 22 pairs of motions from the FEMA P-695 Far Field set (FEMA 2009) and 44 spectrally equivalent longer duration motions from Chandramohan (2016). Here, we add the other horizontal component for each of the 44 long duration motions needed for 3D simulation. These ground motions sets were selected for use in this study because they are well established sets from large magnitude events featuring a wide range of durations and spectral shapes. We also include six record pairs from the New Zealand Strong Motion Database (Van Houtte et al. 2017) to bolster the number of motions with high SaRatio (relative to our target SaRatios) in our suite.

Distributions of SaRatio and $D s_{5-75, N G A}$ in the ground motion set (based on the geomean of each ground motion pair) are summarized in Fig. 7, with target IMs for all six sites at two hazard levels superimposed. Although the distribution of SaRatios in Fig. 7 covers a relatively broad range of values, the target SaRatios are in the upper quartile of those from the ground motions. The median record set duration in terms of $D s_{5-75, N G A}$ is $24.6 \mathrm{~s}$, which exceeds the target durations in all cases; the median record durations is longer than the target because we preferentially chose records that have long durations. 

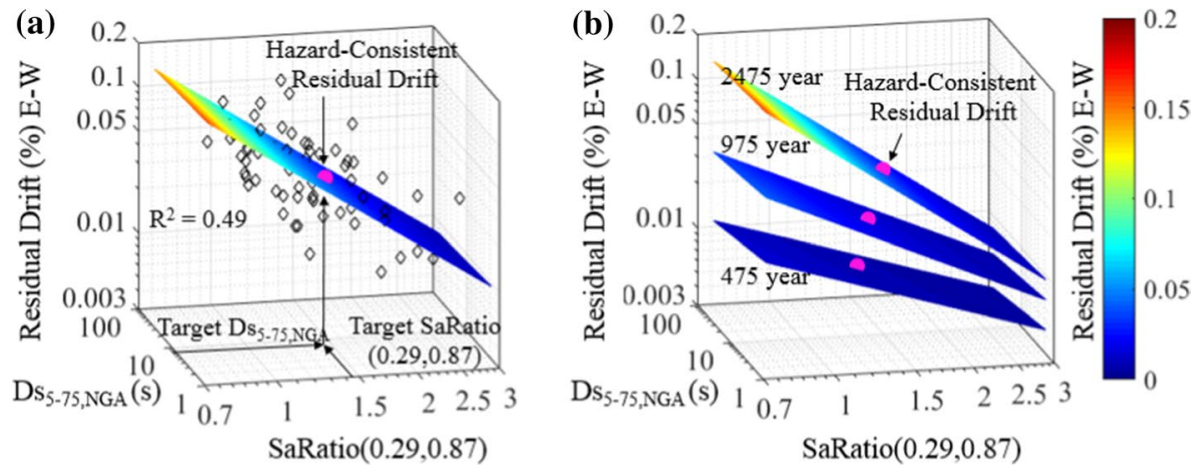

Fig. 8 Illustration of hazard-consistent estimation of EDPs from IDA results for MFD2 in Eugene showing: a linear regression between SaRatio, $D s_{5-75, N G A}$, and residual drift in the E-W direction at the 2475-year hazard level and the underlying data, and b results of linear regressions at the 475, 975, and 2475-year hazard levels for the same IMs and EDP

Fig. 9 Bilinear and linear regressions between SDR and SaRatio, illustrated for MFD1 at the 2745year hazard level

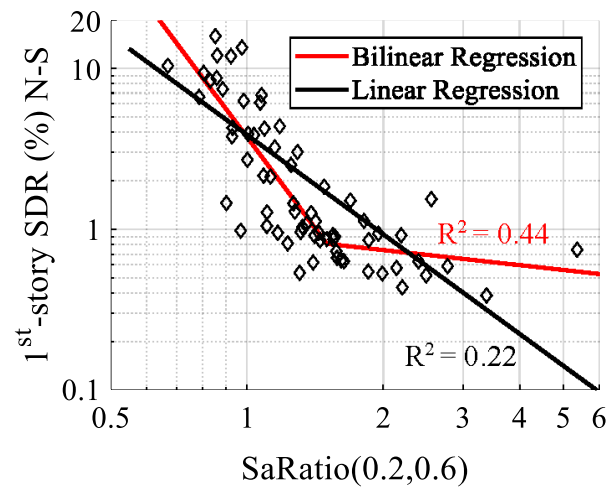

\subsection{Hazard-consistent engineering demand parameter estimates}

To make the HC IDA adjustments (Chandramohan 2016; Zhong et al. 2021) to the response predictions from the generic ground motion set, we develop a multivariate linear regression of our IDA results; Fig. 8 illustrates how these regressions relate EDPs of interest (y-axis) to SaRatio and $D s_{5-75, N G A}$ (x-axis) in natural logarithm (ln-ln) space. The results of this regression are used to produce a median $E D P$ prediction that is conditioned on the target SaRatio and $D s_{5-75, N G A}$. We carried out this regression for several EDPs: peak and residual story drift ratios $(S D R)$ for each story, peak accelerations at each floor, and collapse capacities, in each of the two orthogonal directions independently, at nine hazard levels, for all six buildings. The regression fit is then used to adjust the EDPs to values consistent with the target IMs, as illustrated by the "hazard consistent" EDPs shown in Fig. 8.

The regressions fit the data reasonably well across all EDP and intensity levels, considering $R^{2}$, with the exception of those involving peak SDRs. To obtain hazard-consistent estimates of peak SDRs, we develop instead a bilinear regression between SaRatio and peak $S D R$, as illustrated in Fig. 9. For all of the buildings and hazard levels, we observe a flattening of peak SDR with respect to SaRatio at high values of SaRatio 
that is captured by the bilinear fit. Physically, the spectra with these high SaRatios are so peaked, and with such little energy at periods surrounding $T_{1}$, that small changes in SaRatio do not much impact structural response; a linear regression would therefore underestimate drifts for large SaRatios. The bilinear algorithm, described in detail in Chase (2018), selects the slopes and the kink point based on minimizing the sum of squared errors.

\subsection{Hazard-consistent collapse capacity estimates}

Hazard-consistent median collapse capacities are quantified following the procedure depicted in Fig. 8, but with $S a\left(T_{1}\right)$ at collapse as the EDP of interest (y-axis). Collapse capacities are defined by the geomean $S a\left(T_{1}\right)$, which is consistent with the definition used to define the hazard. In the original formulation of Chandramohan (2016), each part of the collapse fragility curve should be adjusted with the appropriate target IMs at that intensity level. However, Chandramohan et al. (2018) propose a simplification and suggest using disaggregations from an intensity level equal to $2.2 \times \mathrm{MCE}_{\mathrm{R}}$ (this level is suggested because it corresponds to the median collapse capacity for a newly designed Risk Category II structure). Here, we use the shaking intensity corresponding to the 10,000-year hazard level as the basis for target IMs for collapse calculations because the $2.2 \times \mathrm{MCE}_{\mathrm{R}}$ value exceeds this limit of disaggregations provided by the 2014 USGS Hazard Model (Petersen et al. 2014). Chandramohan et al. (2018) showed that adjusting based on a single target level for collapse capacities is sufficient; we also verified this result by comparing hazard-consistent collapse capacity calculations for the simplified approach based on the 10,000-year hazard level with the full convolution, showing differences of an average of $7 \%$.

Figure 10 shows the multivariate regression between the collapse capacities of MFD2 from IDA and the SaRatio and $D s_{5-75, N G A}$ of each ground motion. Collapse capacity is correlated strongly with SaRatio $\left(\mathrm{R}^{2}=0.70\right)$. This strong correlation $\left(\mathrm{R}^{2}>0.7\right)$ with $\operatorname{SaRatio}\left(T_{1}, 3 T_{1}\right)$ was observed for all buildings except MFD1 (for reasons described in Chase 2018). The relationship between collapse capacity and $D s_{5-75, N G A}$ was much weaker for all buildings $\left(\mathrm{R}^{2}<0.15\right)$. We attribute this weak correlation to the relatively low deformation capacities of these buildings, described in more detail below. Previous studies showed that duration effects are most significant for more ductile buildings (Chandramohan et al. 2016a; Raghunandan and Liel 2013).
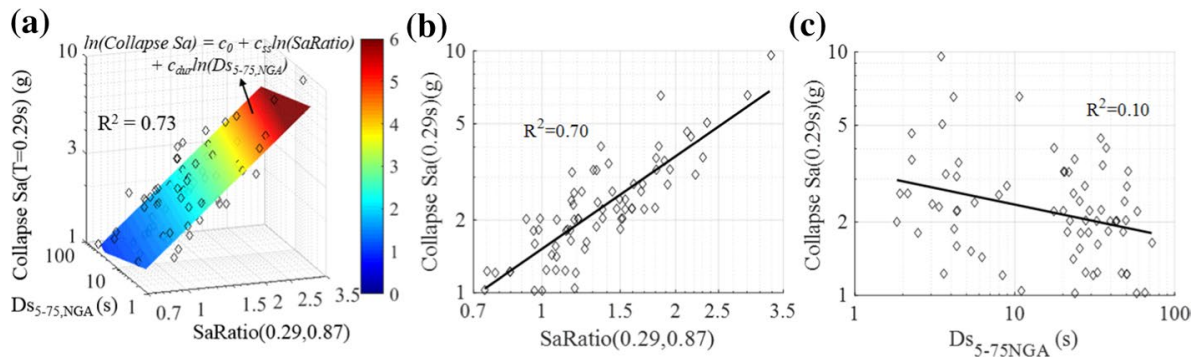

Fig. 10 Regression between collapse capacities of MFD2 and a both $\operatorname{SaRatio}(0.29,0.87)$ and $D s_{5-75, N G A}$, b SaRatio $(0.29,0.87)$, and c $D s_{5-75, N G A}$ independently 


\subsection{Hazard-consistent seismic economic losses}

The SP3 software (Haselton Baker Risk Group 2018) implements the FEMA P-58 methodology (FEMA 2012) and is employed here to estimate hazard-consistent direct economic losses, i.e., earthquake-induced repair costs. FEMA P-58 is an assembly-based loss estimation procedure, in which each building component is associated with fragility models, which represent the probability of that component being in a damage state of interest. These damage states are linked to repair strategies and, ultimately, to expected repair costs or losses. Repair costs for each component are determined from the EDPs from structural analysis (described above) and the component fragility curves. These losses are summed to estimate building repair costs. In addition, collapse, or residual drift of any story exceeding $1 \%$, are assumed to trigger replacement of the entire building (FEMA 2012). The result is a probabilistic estimation of earthquake-induced economic losses, conditioned on hazard level, and obtained through Monte Carlo simulation of EDPs, component damage states, and repair costs.

SP3 takes as input a vector of structural analysis results for each hazard level and EDP of interest. EDPs used for input into SP3 are peak SDR, floor accelerations, residual drift, and collapse capacities. This vector traditionally includes the structural response results for each ground motion used in the simulation, but here these have been adjusted to be hazard consistent. Thus, the hazard-consistent EDPs and correlations between the EDPs as estimated from the IDA are used to produce 1000 EDP realizations for each hazard level, assuming these are lognormally distributed. Correlations among the EDPs can be found in Chase (2018). We quantify the uncertainty in the obtained hazard-consistent EDPs considering the record-to-record variability following the procedure outlined in Chandramohan (2016). Chase (2018) provides more detailed explanation of uncertainty quantification.

\section{Hazard-consistent collapse capacities and design implications}

\subsection{Collapse capacity results}

The estimated median collapse capacities for each building are reported in Table 6, which have been adjusted to be hazard consistent at each site. Because the building designs are the same at all sites, the only differences among the adjusted values at different sites are the ground motion characteristics and target $I M$ s determined from the hazard disaggregations.

As a result of the strong correlation between collapse capacity and spectral shape, location-by-location variation in the (adjusted) median collapse capacity is primarily a function of the target SaRatio (Table 6). The hazard-consistent collapse capacities are higher for all sites and buildings than the unadjusted collapse capacities because all of the target SaRatios are high, indicating ground motions that are less damaging than the ground motions run in IDA (Fig. 7). Eugene, Anchorage, and Portland have the lowest target SaRatio due to large subduction contributions to the hazard and the lowest collapse capacities. Due to the weak correlation between duration and collapse capacity in this study (Fig. 10), the target duration does not have a major influence on the adjusted collapse capacity.

Deep sedimentary basins, like that underlying Seattle, are known to amplify long-period frequency content (e.g., Somerville and Graves 1993; Olsen 2000; Koketsu and Miyake 2008) and are not considered in the numbers above. To investigate the influence of the 
Table 6 Hazard-consistent median collapse capacities for MFD2 and MFD4 at all sites, together with target SaRatios and $D s_{5-75, N G A}$ (at the 10,000-year hazard level)

\begin{tabular}{|c|c|c|c|c|c|c|}
\hline & \multicolumn{3}{|c|}{$\operatorname{MFD} 2\left(\mathrm{~T}_{1}=0.29 \mathrm{~s}\right)$} & \multicolumn{3}{|c|}{$\operatorname{MFD} 4\left(T_{1}=0.51 \mathrm{~s}\right)$} \\
\hline & \multicolumn{2}{|c|}{ Target IMs } & \multirow{2}{*}{$\begin{array}{l}\text { Collapse } \\
\text { Capacity, } \\
\mathrm{Sa}\left(T_{1}\right) \\
{[\mathrm{g}]}\end{array}$} & \multicolumn{2}{|c|}{ Target IMs } & \multirow{2}{*}{$\begin{array}{l}\text { Collapse } \\
\text { Capacity, } \\
\text { Sa }\left(T_{1}\right) \\
{[\mathrm{g}]}\end{array}$} \\
\hline & SaRatio & $D s_{5-75, N G A}[s]$ & & SaRatio & $D s_{5-75, N G A}[s]$ & \\
\hline Los Angeles & 3.0 & 4.0 & 5.9 & 3.5 & 4.7 & 3.0 \\
\hline San Francisco & 2.3 & 6.9 & 4.3 & 2.6 & 8.9 & 2.1 \\
\hline Seattle & 2.3 & 3.5 & 4.5 & 2.6 & 4.2 & 2.1 \\
\hline Portland & 1.9 & 4.5 & 3.4 & 2.3 & 5.6 & 1.8 \\
\hline Anchorage & 1.6 & 5.3 & 2.9 & 2.5 & 7.5 & 2.0 \\
\hline Eugene & 1.6 & 8.5 & 2.8 & 2.2 & 9.8 & 1.8 \\
\hline $\begin{array}{l}\text { Unadjusted (Not } \\
\text { hazard consist- } \\
\text { ent) }\end{array}$ & - & - & 2.1 & - & - & 1.5 \\
\hline
\end{tabular}

Values for MFD1, COM1, COM2, and COM4 can be found in Chase (2018)

basin on collapse capacities in Seattle, we examine results of the M9 Project (Frankel et al. 2018; Marafi et al. 2017). In the M9 Project, 3D synthetic ground motions were generated from 30 MW 9.0 earthquake rupture scenarios on the interface of the Juan De Fuca and North American Plates. Ground shaking time series were simulated at sites inside and outside the Seattle Basin. From the reported spectra in Frankel et al. (2018), we calculated representative $\operatorname{SaRatio}(0.2,0.6)$ values inside and outside the basin to be 0.91 and 0.88 , respectively; for $\operatorname{SaRatio}(0.5,1.5)$, the values are 1.1 and 1.7. Our target SaRatios were 2.2 and 2.6 for these two period ranges, i.e., much more peaked/less damaging. These differences come from two sources. First, the hazard disaggregation considers multiple scenario earthquakes, with a $\mathrm{M}_{\mathrm{W}} 9$ interface earthquake that is most like that considered in the M9 Project only having about $10 \%$ contribution to hazard at the 10,000-year hazard level in Seattle (Petersen et al. 2014); these different source types (including the crustal Seattle fault) and magnitude levels in the hazard disaggregation both affect SaRatio. Second, the effects of basins are not fully captured in the 2014 Hazard Model (Petersen et al. 2014). The effect of the second factor is expected to result in more damaging SaRatio (both inside and outside the Seattle Basin, but with more significant effects in the basin), which would lower the collapse capacities estimated for Seattle relative to the values reported here. For future work, the 2018 USGS 2018 Hazard Model (Petersen et al. 2014) now includes basin effects in Seattle, Los Angeles, San Francisco, and Salt Lake City.

\subsection{Modified design values to achieve uniform collapse fragilities and risk}

\subsubsection{Framework}

In the United States, the NEHRP Provisions (FEMA 2015), and the ASCE 7 Standard (ASCE 2016) and IBC (ICC 2018) that reference these provisions, have formally adopted risk-targeted values for determination of seismic design base shear. These risk-targeted mapped $S a$ values (referred to as $M C E_{R}$ ) aim to ensure that a code-designed building having the "generic" collapse fragility defined in FEMA (2015) will have 1\% probability of 
collapse in 50 years (where not deterministically capped). These risk-targeted design values consider that the shape and $S a$ of the seismic hazard curve vary from site to site (and with spectral period and site class), but they do not consider the effects of ground motion frequency content and duration. To preliminarily consider duration impacts for seismic design codes, Liel et al. (2015) calculated new $M C E_{R}$ values by modifying the "generic" collapse fragility curves to account for the duration and spectral shape of subduction events, showing that such an approach would produce significant increases in design values at some sites.

Chandramohan et al. (2018) proposed a framework that adjusts design $S a$ values to account for ground motion characteristics such as spectral shape and ground motion duration and their influence on risk. In particular, Chandramohan et al. (2018) defined modification factors for spectral shape $\left(k_{s s}^{\prime}\right)$ and for duration $\left(k_{d u r}^{\prime}\right)$, to be applied to the design base shear:

$$
V=k_{s s}^{\prime} k_{d u r}^{\prime} C_{s} W
$$

$V$ is the design base shear, $C_{s}$ is the seismic response coefficient based on mapped values in ASCE 7 (i.e., $M C E_{R}$ ), considering the building period and structural system, and $W$ is the seismic weight. $k_{s s}^{\prime}$ and $k_{d u r}^{\prime}$ account for differences in building collapse fragilities due to ground motion characteristics other than spectral intensity, relative to a reference site:

$$
\begin{gathered}
k_{s s}^{\prime}=\left(\frac{\text { SaRatio }^{\text {ref }}}{\text { SaRatio }^{\text {site }}}\right)^{c_{s s}} \\
k_{d u r}^{\prime}=\left(\frac{D s^{r e f}}{D s^{\text {site }}}\right)^{c_{\text {dur }}}
\end{gathered}
$$

This formulation assumes the median collapse capacity is linearly proportional to the design value in order to level seismic collapse risk across sites (Chandramohan et al. 2018). Here, SaRatio ${ }^{\text {site }}$ and $D s^{\text {site }}$ are the median target SaRatio and $D s_{5-75, N G A}$ at the hazard level of interest for collapse (here, the 10,000-year return period). SaRatio ${ }^{\text {ref }}$ and $D s^{\text {ref }}$ are the corresponding values at a reference site or group of sites. We consider the choice of reference site below. $c_{s s}$ and $c_{\text {dur }}$ quantify the sensitivity of a structure to the effects of spectral shape and duration, defined in Fig. 10.

The $c_{s s}$ and $c_{\text {dur }}$ factors from our archetype wood frame buildings and the buildings analyzed in Chandramohan (2016) are plotted in Fig. 11, with respect to the buildings' fundamental periods, a building characteristic that is important for both $c_{s s}$ and $c_{\text {dur }}$ (Chandramohan 2016). We note that the precision of $c_{s s}$ and $c_{d u r}$ could potentially be improved through the addition of more ground motion records to bring the median SaRatio and Ds $s_{5-75, N G A}$ of the ground motion records closer to the target values of the sites (Fig. 7), but we do not expect these changes to significantly alter the calculated values.

Figure 11 also shows the curve fit to these data by Chandramohan (2016) and an updated fit developed here with the WLF data added. The results for $c_{s s}$ show that WLF buildings are relatively consistent with the trends of other buildings previously assessed in Fig. 11a, provided period is considered. (The exception is MFD1, for reasons described in Chase 2018). For $c_{d u r}$, however, this study's WLF buildings do not show as much dependence on duration as the other four structure types. Statistically, all values of $c_{d u r}$ are small (and p-values associated with the $c_{d u r}$ from the regression in Fig. 10a are large, indicating 

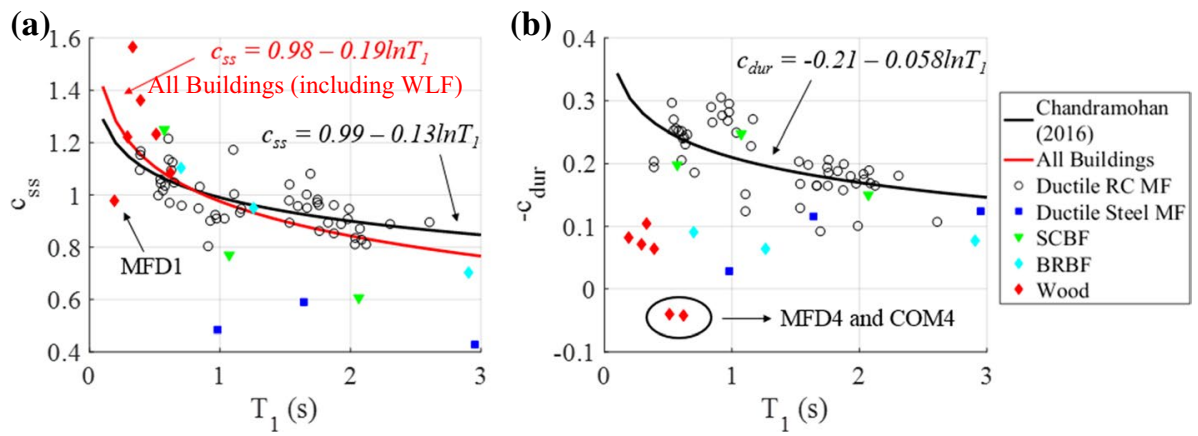

Fig. $11 \mathbf{a} c_{s s}$ and $\mathbf{b}-c_{d u r}$ factors for different structural systems. These terms are defined in Fig. 10a

insignificance). We attribute the lack of dependence on duration to the structures' relatively lower deformation capacities (mean deformation capacity, $\mu_{T}$, of 8.5 in Chandramohan (2016) vs. 4.6 here). As a result, we do not develop $k_{d u r}^{\prime}$ factors for these buildings and suggest more generally that $k_{d u r}^{\prime}$ should be dependent on deformation capacity of a structure. These considerations indicate that period and deformation capacity are the most critical building parameters to consider in definition of $c_{s s}$ and $c_{d u r}$; because these parameters are already defined in the ASCE 7 Standard, this approach captures the most important building and system-related parameters without undue complexity for each building.

The reader may recall that we did not redesign the buildings at each site. This assessment uses only the coefficients with respect to SaRatio (and duration) defined in Fig. 10a, which would not be strongly influenced by building strength/redesign. We further note that the approach is agnostic to the origin of the design base shear coefficient, i.e., Cs, particularly whether it is based on a truly probabilistic $M C E_{R}$, or the site is affected by deterministic capping of design values (Luco et al. 2017). However, if the design value is not risk targeted, the target collapse risk may not be achieved even with the adjustments (Luco et al. 2017; Cook et al. 2019).

\subsection{Modified design values}

The resulting spectral shape adjustment to the design values, $k_{s s}$, for all of the sites at two periods are reported in Table 7. These $k_{s s}^{\prime}$ values use $c_{s s}$ from the "All Buildings" fitted curve in Fig. 11a. We consider three different definitions of reference "sites" in Eq. (3), with implications examined in Table 7.

The first two reference sites of interest are Los Angeles and San Francisco. These sites were selected by Chandramohan et al. (2018) because the ground motions and damage experience that have dominated the development of U.S. seismic design are from crustal sites in the western United States like these two cities. When Los Angeles is the reference site, $k_{s s}^{\prime}>1$ for all other sites, corresponding to an increase in design base shear ranging from 36 to $141 \%$ at the other sites. Compared to Los Angeles, other sites have less peaked, more damaging spectra (lower target SaRatios), necessitating higher design values to achieve collapse risk goals. Our sites with the largest subduction hazard contributions have the largest $k_{s s}$ due to low expected SaRatios. However, San Francisco also has a $k_{s s}^{\prime}>1$ because of the importance of relatively large magnitude $\left(\mathrm{M}_{\mathrm{W}}>7.2\right)$ crustal earthquakes at closer distances compared to Los Angeles, which lowers target SaRatios. 
Table 7 Calculated design modification, $k_{s s}$, factors at $0.2 \mathrm{~s}$ and $0.5 \mathrm{~s}$ at each site for three different reference "sites."

\begin{tabular}{|c|c|c|c|c|c|}
\hline \multirow[b]{2}{*}{ Site } & \multirow[b]{2}{*}{ Period $\left(\mathrm{T}_{1}\right)[\mathrm{s}]$} & \multirow{2}{*}{$\begin{array}{l}10,000- \\
\text { yr Target } \\
\text { SaRatio }\end{array}$} & Site $^{\text {ref }}=$ Los Angeles & Site $^{\text {ref }}=$ San Francisco & $\begin{array}{l}\text { Site }^{\text {ref }}=\text { Aver- } \\
\text { age of All } 6 \\
\text { Sites }\end{array}$ \\
\hline & & & $10,000-\mathrm{yr} k_{s s}^{\prime}$ & $10,000-\mathrm{yr} k_{s s}^{\prime}$ & $10,000-\mathrm{yr} k_{s s}^{\prime}$ \\
\hline \multirow[t]{2}{*}{ Los Angeles } & 0.2 & 2.7 & 1.0 & 0.7 & 0.6 \\
\hline & 0.5 & 3.5 & 1.0 & 0.7 & 0.7 \\
\hline \multirow[t]{2}{*}{ San Francisco } & 0.2 & 2.2 & 1.4 & 1.0 & 0.9 \\
\hline & 0.5 & 2.6 & 1.4 & 1.0 & 1.0 \\
\hline \multirow[t]{2}{*}{ Seattle } & 0.2 & 2.2 & 1.3 & 1.0 & 0.8 \\
\hline & 0.5 & 2.6 & 1.4 & 1.0 & 1.0 \\
\hline \multirow[t]{2}{*}{ Portland } & 0.2 & 1.7 & 1.9 & 1.4 & 1.2 \\
\hline & 0.5 & 2.3 & 1.6 & 1.2 & 1.2 \\
\hline \multirow[t]{2}{*}{ Anchorage } & 0.2 & 1.4 & 2.3 & 1.7 & 1.5 \\
\hline & 0.5 & 2.5 & 1.5 & 1.1 & 1.1 \\
\hline \multirow[t]{2}{*}{ Eugene } & 0.2 & 1.4 & 2.4 & 1.8 & 1.5 \\
\hline & 0.5 & 2.2 & 1.6 & 1.2 & 1.2 \\
\hline
\end{tabular}

With San Francisco as a reference site (Table 7), Los Angeles and Seattle have $k_{s s}^{\prime}<1.0$, i.e., a decrease in design base shear. In this case, the increase in Eugene would be up to $80 \%$. These results are potentially problematic because they indicate a big difference in design values depending on the reference site, even when two reference sites with their entire hazard comprising only crustal source types are considered. We find no clear justification which of these sites is a more appropriate reference site choice.

A third alternative for a reference site is to take the SaRatio from the average of a group of sites. In concept, for example, this could be calculated for all of the sites in SDC D, as was done for the spectral shape factor (SSF) in FEMA P-695 (FEMA 2009), which was used in developing the generic collapse fragility that is the basis for $M C E_{R}$ and modern U.S. design provisions. For illustration, we take SaRatio ${ }^{\text {ref }}$ as the average of the targets for the six sites considered here. This method leads to reduction of design base shear at sites with the most peaked expected spectral shape (up to 40\%) and an increase in base shears at the sites with flatter expected spectral shapes (up to 50\%). It is likely that a reference site that averages these effects across much of SDC D where crustal hazards are dominant would be appropriate.

\section{Hazard-consistent seismic economic losses}

Hazard-consistent seismic economic losses are generated and illustrated in Fig. 12 for the three commercial buildings at all six sites; results for all buildings are provided in Chase (2018). For a given building and intensity of shaking, if the building is located at the sites with the largest subduction contributions, the seismic losses will be greater. For example, for COM2 in Fig. 12b, at $S a(T=0.39 s)=1.0 \mathrm{~g}$ the expected seismic losses in Anchorage are approximately 33\% greater than in Los Angeles and Seattle. As with collapse capacities, spectral shape has a much larger impact on the outcome of the assessment of economic losses than duration $\left(R^{2}=0.70\right.$ vs. $R^{2}=0.10$ in Fig. $10 \mathrm{~b}, \mathrm{c}$ 

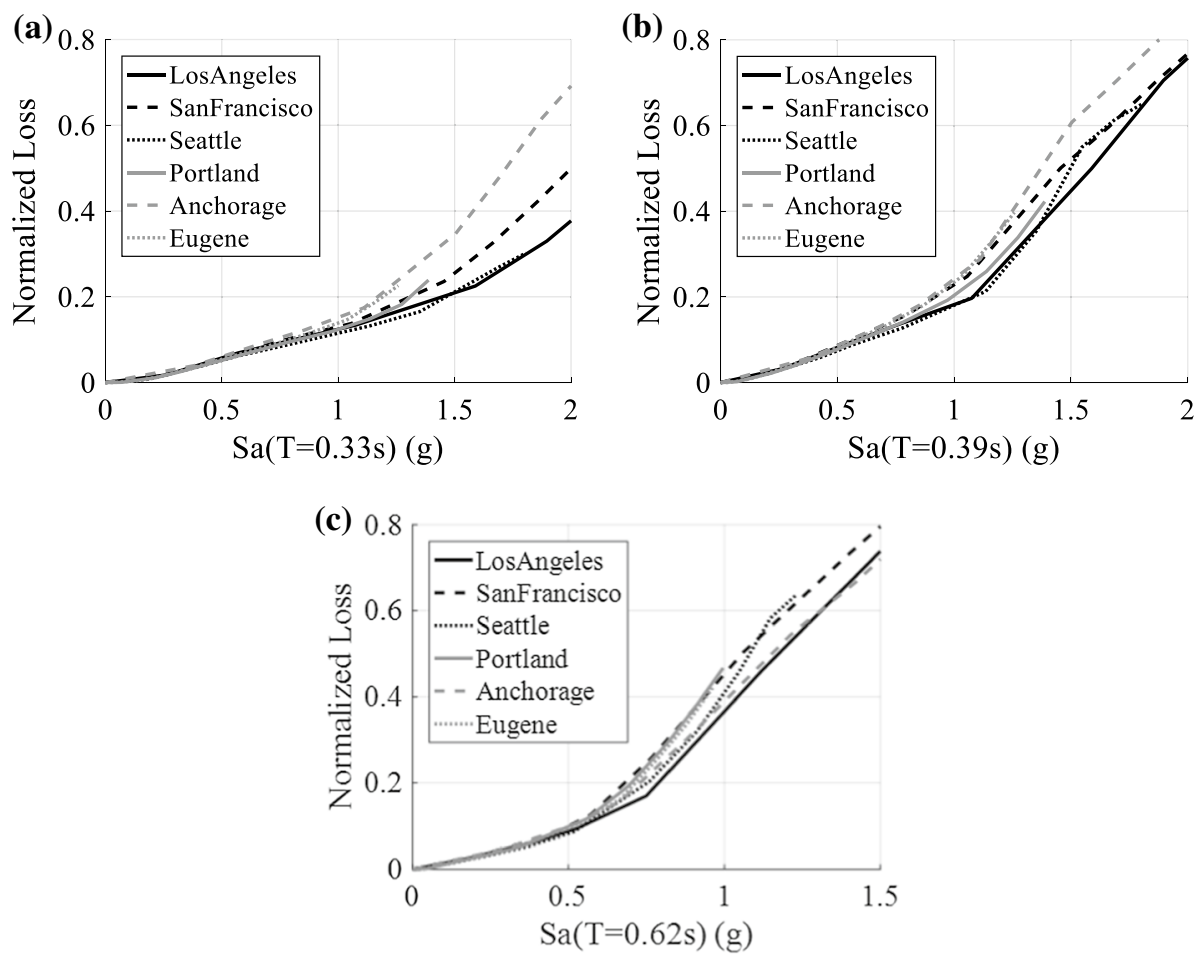

Fig. 12 Mean hazard-consistent economic losses, normalized by the replacement cost of each building, and plotted as a function $\mathrm{Sa}\left(\mathrm{T}_{1}\right)$ for: a COM1, b COM2, and $\mathbf{c} \mathrm{COM} 4$

respectively). The difference in loss widens at higher intensities because of the bigger difference among the sites in the target SaRatios at these intensities. These differences are more apparent for the shorter buildings. For these buildings, collapse capacity and losses are more correlated with SaRatio because the damage is concentrated in a single story. In the taller buildings, damage is mostly in the first (critical) story, but the losses upstairs weaken the correlation with spectral shape.

Fig. 13 Mean hazard-consistent economic loss for MFD2, normalized by the replacement cost for MFD2, and plotted as a function of hazard level

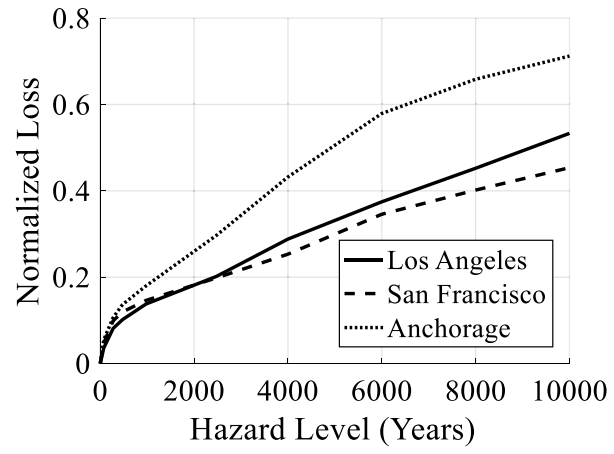


The expected seismic losses for MFD2 at three sites as a function of hazard level rather than $S a$ is compared in Fig. 13. Although each site has different Sas associated with each hazard level, the biggest difference between Anchorage and San Francisco is 26\% (or $0.08 \mathrm{~g}$ ) at the 75-year return period. Los Angeles has slightly higher expected intensities at hazard levels beyond the 975-year return period compared to both other sites, with the largest difference being $20 \%(0.43 \mathrm{~g})$ at the 10,000-year return period. At all hazard levels, if the two-story multifamily building is located in Anchorage, it has a higher expected loss than if it were located in San Francisco or Los Angeles, with losses 8 to $71 \%$ greater depending on the hazard level. In other words, even though Los Angeles has a higher shaking intensity at a hazard level of interest (e.g., $S a\left(T_{1}=0.29 \mathrm{~s}\right)=1.59 \mathrm{~g}$ for Los Angeles vs. $S a\left(T_{1}=0.29 \mathrm{~s}\right)=1.50 \mathrm{~g}$ for Anchorage at the 2475-year hazard level), the losses are still higher in Anchorage; the more damaging seismic environment in terms of spectral shape and durations in Anchorage more than outweighs the effect of greater $S a\left(T_{1}\right)$ in Los Angeles. Similar trends are observed for the other buildings (not shown).

\section{Conclusions and future work}

This study assesses expected seismic economic losses and collapse capacities of WLF buildings considering region-specific seismic environments and its impact on ground motion frequency content and duration. To do so, we simulated the nonlinear dynamic response of multifamily residential and commercial WLF buildings at six sites and estimated seismic direct economic losses and collapse risks using the hazard-consistent IDA methodology. Assessments of collapse capacity are used to illustrate potential modifications for U.S. seismic design values in ASCE 7 to level collapse risks across different seismic regions. We also advance some of the details of the hazard-consistent methodology to compare results at sites with subduction and crustal hazards.

The results show that the response of these WLF buildings correlates strongly with spectral shape but only weakly with ground motion duration. We attribute the weak correlation with duration to the relatively low deformation capacity of these buildings when compared to the RC and steel buildings examined in other ground motion duration studies. Considering the hazard in different tectonic environments, spectra tend to be more peaked and less damaging (higher SaRatios) at sites dominated by crustal hazards and lower (more damaging) at sites dominated by subduction hazards.

As a result of these trends, sites with larger contributions from subduction hazards have lower expected collapse capacities and higher expected earthquake-induced economic losses for these WLF buildings. For the same building, collapse capacities can differ by up to a factor of 2 as a result of spectral shape influences from hazard. In terms of losses, estimated economic losses, conditioned on $\mathrm{Sa}\left(T_{1}\right)$, can differ by about a factor of 2 between Los Angeles and Anchorage.

Some of these differences may be mitigated by using design modification factors that could amplify design in places where the seismic environment is potentially more damaging. The procedure for developing these factors (Chandramohan et al. 2018) involves first selecting a reference "site" that is consistent with the development of ASCE 7 design provisions and risk-targeted ground motions; other design values are modified relative to this site. The reference sites considered suggest large changes in design values may be warranted. However, the results obtained are heavily dependent on the selected reference site. 
We suggest that it is likely appropriate to base the reference on a group of sites in SDC D where ground motion and damage data are well established.

This paper makes the case that seismic risks of code-designed buildings remain quite variable across sites with high seismic hazard. As shown here, this variation could be reduced by modifying design base shear to account for expected ground motion frequency content (and likely duration for buildings that are more ductile than WLF). Other changes in seismic design might facilitate these investigations. First, the 2020 NEHRP Provisions (FEMA 2020a, b) have defined design values at a larger number of periods (22) ranging from 0 to $10 \mathrm{~s}$. These could be, but have not yet been, used to capture the spectral shape issues. In addition, the 2018 USGS hazard model and 2020 NEHRP Provisions include some of the basin effects that would be important in modifying seismic design values for Seattle and other cities on large basins.

Lastly, this study examines newly built multifamily and commercial WLF construction. Studying single family residences and existing WLF construction would be a logical next step since these represent a large portion of the building stock throughout the United States.

Acknowledgements Funding was provided by the National Science Foundation (NSF) under Grant \#1515438. The authors gratefully acknowledge the input of Jack Baker, Reagan Chandramohan, Greg Deierlein, Marc Eberhard, Art Frankel, Nasser Marafi, Melanie Walling, Lizhong Zhang, Kuanshi Zhong, Brian Shiro and one anonymous reviewer. Any use of trade, firm, or product names is for descriptive purposes only and does not imply endorsement by the U.S. Government.

Funding Funding was provided by the National Science Foundation (NSF) under Grant \#1515438.

Availability of data and material Any data or materials presented in this study is available upon request.

Code availability Codes used in this study are available upon request.

\section{Declarations}

Conflicts of Interest Not applicable.

Open Access This article is licensed under a Creative Commons Attribution 4.0 International License, which permits use, sharing, adaptation, distribution and reproduction in any medium or format, as long as you give appropriate credit to the original author(s) and the source, provide a link to the Creative Commons licence, and indicate if changes were made. The images or other third party material in this article are included in the article's Creative Commons licence, unless indicated otherwise in a credit line to the material. If material is not included in the article's Creative Commons licence and your intended use is not permitted by statutory regulation or exceeds the permitted use, you will need to obtain permission directly from the copyright holder. To view a copy of this licence, visit http://creativecommons.org/licenses/by/4.0/.

\section{References}

Abrahamson N, Kuehn N, Gulerce Z, Gregor N, Bozorgnia Y, Parker G, Youngs R (2018) Update of the BC Hydro subduction ground-motion model using the NGA-subduction dataset. PEER Report 2018/02, p 97

Afshari K, Stewart J (2016) Physically parameterized prediction equations for significant duration in active crustal regions. Earthq Spectra 32(4):2057-2081

ASCE (2010) Minimum design loads for buildings and other structures. ASCE/SEI 7-10. ASCE, Washington DC, p 253

ASCE (2016) Minimum design loads for buildings and other structures. ASCE/SEI 7-16. ASCE, Washington DC, p 800 
Bahrampouri M, Rodriguez-Marek A, Green RA (2020) Ground motion prediction equations for significant duration using the KiK-net database. Earthq Spectra 37(2):903-920

Baker J (2011) Conditional mean spectrum: tool for ground-motion selection. J Struct Eng 137(3):322-331

Baker J, Cornell C (2006) Spectral shape, epsilon and record selection. Earthq Eng Struct Dyn 35(9):1077-1095

Baker J, Jayaram N (2008) Correlation of spectral acceleration values from NGA ground motion models. Earthq Spectra 24(1):299-317

Bommer J, Stafford P, Alarcón J (2009) Empirical equations for the prediction of the significant, bracketed, and uniform duration of earthquake ground motion. Bull Seismol Soc Am 99(6):3217-3233

Bradley B (2010) A conditional intensity measure approach and holistic ground-motion selection. Earthq Eng Struct Dyn 39(12):1321-1342

Bradley B (2011) Correlation of significant duration with amplitude and cumulative intensity measures and its use in ground motion selection. J Earthq Eng 15(6):809-832

Campbell K, Bozorgnia Y (2014) NGA-West2 ground motion model for the average horizontal components of PGA, PGV, and 5\% damped linear acceleration response spectra. Earthq Spectra 30(3):1087-1115

Chandramohan R (2016) Duration of earthquake ground motion: Influence on structural collapse risk and integration in design and assessment practice. Stanford University. $\mathrm{PhD}$ Thesis, $\mathrm{p} 448$

Chandramohan R, Baker J, Deierlein G (2016) Quantifying the influence of ground motion duration on structural collapse capacity using spectrally equivalent records. Earthq Spectra 32(2):927-950

Chandramohan R, Baker J, Deierlein G (2018) Accounting for the influence of ground motion response spectral shape and duration in the equivalent lateral force design procedure. In: 11th national conference in earthquake engineering. Los Angeles, CA, p 11

Chase R (2018) Structural response and risk considering regional ground motion characteristics. Univerity of Colorado Boulder: PhD Thesis, p 178

Cook D, Liel A, Luco N, Haselton C (2019) Implications of seismic design values for economic loss. In: 13th international conference on applications of statistics and probability in civil engineering. Seoul, Korea, $\mathrm{p} 8$

Eads L, Miranda E, Lignos D (2015) Average spectral acceleration as an intensity measure for collapse assesment. Earthq Eng Struct Dyn 42(12):2057-2073

Eads L, Miranda E, Lignos D (2016) Spectral shape metrics and structural collapse potential. Earthq Eng Struct Dyn 45(10):1643-1659

FEMA (2009) FEMA P-695 Quantification of building seismic performance factors. Federal Emergency Management Agency, Washington DC, p 421

FEMA (2012) FEMA P-58-1: Seismic performance assessment of buildings. Volume 1-Methodology. Federal Emergency Management Agency, Washington, D.C., p 340

FEMA (2015) NEHRP recommended seismic provisions for new buildings and other structures, Part 1: Provisions, Part 2: Commentary. Federal Emergency Management Agency, Washington, D.C., p 555

FEMA (2020) 2020 NEHRP recommended seismic provisions, Part 1: Provisions, Part 2: Commentary. Federal Emergency Management Agency, Washington D.C., p 593

FEMA (2020) FEMA P-2139-2, Short-period building collapse performance and recommendations for improving seismic design, Volume 2-study of one-to-four story wood light-frame buildings. Federal Emergency Management Agency, Washington, D.C., p 366

Filiatrault A, Isoda H, Folz B (2003) Hysteretic damping of wood framed buildings. Eng Struct 25(4):461-471

Folz B, Filiatrault A (2001) Cyclic analysis of wood shear walls. J Struct Eng 127(4):433-441

Folz B, Filiatrault A (2004) A computer program for seismic analysis of woodframe structures. Consortium of Universities for Research in Earthquake Engineering. Richmond, California, CUREE Publication W-21, p 114

Folz B, Filiatrault A (2004b) Seismic analysis of woodframe structures. II: model implementation and verification. J Struct Eng 130(9):1361-1370

Frankel A, Wirth E, Marafi N, Vidale J, Stephenson W (2018) Broadband synthetic seismograms for magnitude 9 earthquakes on the cascadia megathrust based on 3D simulations and stochastic synthetics, part 1: methodology and overall results. Bull Seismol Soc Am 108(5A):2347-2369

Furumura T, Takemura S, Noguchi S, Takemoto T, Maeda T, Iwai K, Padhy S (2011) Strong ground motions from the 2011 off-the Pacific-Coast-of-Tohoku, Japan $(\mathrm{Mw}=9.0)$ earthquake obtained from a dense nationwide seismic network. Landslides 8(3):333

Ghehnavieh E (2017) Seismic analysis of light-frame wood building with a soft-story deficiency. Clemson University. Clemson University: PhD Thesis, p 247

Hancock J, Bommer J (2007) Using spectral matched records to explore the influence of strong-motion duration on inelastic structural response. Soil Dyn Earthq Eng 27(4):291-299

Haselton Baker Risk Group (2018) Seismic performance prediction program. Chico, California. Retrieved from http://hbrisk.com 
ICC (2018) International building code. International Code Counci. Retrieved from https://codes.iccsafe.org/ content/IBC2018P5

Iervolino I, Manfredi G, Cosenza E (2006) Ground motion duration effects on nonlinear seismic response. Earthq Eng Struct Dyn 35(1):21-38

Jalayer F (2003) Direct probablistic seismic analysis: implementing non-linear dynamic assesments. Stanford University: PhD Thesis, $\mathrm{p} 244$

Koketsu K, Miyake H (2008) A seismological overview of long-period ground motion. J Seismol 12(2):133-143

Liel A, Luco N, Raghunandan M, Champion C (2015) Modifications to risk-targeted seismic design maps for subduction and near-fault hazards. In: 12th international conference on applications of statistics and probability in civil engineering, ICASP12. Vancouver, p 8

Luco N, Liu T, Rukstales K (2017) A risk-targeted alternative to deterministic capping of maximum considered earthquake ground motion maps. In: 16th World conference on earthquake engineering. Santiago, Chile, $\mathrm{p} 12$

Marafi N, Eberhard M, Berman J, Wirth E, Frankel A (2017) Effects of deep basins on structural collapse during large subduction earthquakes. Earthq Spectra 33(3):963-997

Mohammed M, Sanders D, Buckle I (2015) Shake table tests of reinforced concrete bridge columns under long duration ground motions. In: 6th international conference on advances in experimental structural engineering. Urbana-Champaign, IL, $\mathrm{p} 8$

NIST (2011) Selecting and scaling earthquake ground motions for performing response-history analyses, NIST GCR 11-917-15. National Institute of Standards and Technology, p 256

Olsen KB (2000) Site amplification in the Los Angeles basin from three-dimensional modeling of ground motion. Bull Seismol Soc Am 90(6B):277-294

Pan Y, Ventura C, Finn W (2018) Effects of ground motion duration on the seismic performance and collapse rate of light-frame wood houses. J Struct Eng 144(8):04018112

Pang W, Shirazi S (2013) Corotational model for cyclic analysis of light-frame wood shear walls and diaphragms. ASCE J Struct Eng Special issue NEES 2: Advances in Earthquake Engineering, 139(8):1303-1317

Pang W, Ziaei E, Filiatrault A (2012) A 3d model for collapse analysis of soft-story light-frame wood buildings. In: World conference on timber engineering. Auckland, NZ

Pei S, van de Lindt J (2011) Seismic numerical modeling of a six-story light-frame wood building: comparison with experiments. J Earthq Eng 15(6):924-941

Pei S, van de Lindt J, Wehbe N, Liu H (2012) Experimental study of collapse limits for wood frame shear walls. J Struct Eng 139(9):1489-1497

Petersen MD, Moschetti MP, Powers PM, Mueller CS, Haller KM, Frankel AD, . . Wheeler R (2014) Documentation for the 2014 update of the United States national seismic hazard maps. U.S. Geological Survey Open-File Report 2014-1091, p 255

Raghunandan M, Liel A (2013) Effect of ground motion duration on earthquake-induced structural collapse. Struct Saf 41:119-133

Raghunandan M, Liel AB, Luco N (2015) Aftershock collapse vulnerability assessment of reinforced concrete frame structures. Earthq Eng Struct Dyn 44(3):419-439

Somerville P, Graves R (1993) Conditions that give rise to unusually large long period ground motions. Struct Des Tall Build 2(3):211-232

Trifunac M, Brady A (1975) A study on the duration of strong earthquake ground motion. Bull Seismol Soc Am 65(3):581-626

USGS (2018) Unified Hazard Tool. Retrieved from https://earthquake.usgs.gov/hazards/interactive/

Vamvatsikos D, Cornell CA (2002) Incremental dynamic analysis. Earthq Eng Struct Dyn 31(3):491-514

van de Lindt J, Pei S, Liu H, Filiatrault A (2009) Three-dimensional seismic response of a full-scale light-frame wood building: Numerical study. J Struct Eng 136(1):56-65

Van Houtte C, Bannister S, Holden C, Bourguignon S, McVerry G (2017) The New Zealand strong motion database. Bull N Z Soc Earthq Eng 50(1):1-20

Walling M, Kuehn N, Abrahmson N, Mazzoni S (2018) Regional ground motion duration prediction model for subduction regions. In: 11th national conference in earthquake engineering. Los Angeles, CA

Zhong K, Lin T, Deierlein G, Graves R, Silva F, Luco N (2021) Tall building performance-based seismic design using SCEC broadband platform site-specific ground motion simulations. Earthq Eng Struct Dyn 50(1):81-98

Publisher's Note Springer Nature remains neutral with regard to jurisdictional claims in published maps and institutional affiliations. 